\title{
Lessons for Staff Development: Lecturers' Transition from Face-to-Face to Online Teaching for Masters Courses in Higher Education
}

\author{
Alison Clapp \\ Correspondence: Alison Clapp, Newcastle University Faculty of Medical Sciences Graduate School, Taught Postgraduate \\ Office, Ridley $3^{\text {rd }}$ Floor, Queen Victoria Road, Newcastle-upon-Tyne, United Kingdom NE1 7RU
}

Received: May 29, 2021

doi:10.11114/ijce.v4i2.5248

\author{
Accepted: June 29, $2021 \quad$ Online Published: July 6, 2021
}

URL: https://doi.org/10.11114/ijce.v4i2.5248

\begin{abstract}
During the COVID-19 pandemic there has been an almost universal pivot to emergency online teaching in higher education, requiring staff development as online teaching differs from teaching face-to-face. The transition has been at short notice, with rapidly created training and little time to engage. Past research into the transition to teach online is scarce. The study described here, carried out in the year before COVID-19, aimed to investigate the how previous experiences of learning and training affected transition, and how staff made sense of the experience, adding to knowledge on successful transition to teaching online distance learning courses. Interpretive phenomenological analysis was carried out after interviewing five experienced online teaching staff in a Graduate School, using semi-structured interviews and open-ended questioning. The overarching themes found were connections to online learning and teaching communities, and developing membership of, and activities in, these communities themselves. Staff with good connections to the online teaching community via other experienced staff, training, and prior experience as online students were able to make the transition to teach online with comparative ease, compared to those who did not. With little connection to the online teaching community, transition was slow and staff retained a greater connection to face-to-face teaching and its community. Post-pandemic, the study suggests that designs for staff development, relational agency (working for short periods with online teaching experts) and situated learning within an online environment are beneficial if elements of online learning and teaching are to be retained for the future.
\end{abstract}

Keywords: staff development, online teaching, community, connection, online training, mentor

\section{Introduction}

During 2020, the COVID-19 pandemic forced universities to pivot their courses online, increasing the requirement for staff development. 'Emergency' teaching differs from full online teaching, being a rapid stop-gap. Online teaching, carried out for many years previously, may use constructivist approaches leading to collaboration, with courses developed over a longer time period. Since the first online courses, to the present day, attitudes towards teaching online, and availability and accessibility of staff training to develop their online teaching skills, have been both barriers and opportunities for success (Clay 1999, Aitken \& Loads, 2019). Whilst there has been a myriad of case studies published on staff development in the past, there have been fewer studies investigating how prior experiences of online education, as well as engagement with staff development opportunities, influences attitudes towards online education (Rolfe, Alcocer, Bentley, Milne \& Meyer-Sahling, 2006).

Prior to the pandemic, an ethnographic study of an e-learning team within a UK higher education institution (HEI) Graduate School, involved in supporting online learning, found staff tasked with running these courses having taught only on campus previously, showed a great deal of trepidation at the prospect (Clapp, 2017). Lack of confidence has been mentioned in other studies (Maguire, 2005, King \& Boyatt, 2015), with identity threat or dissonance common (Maggio, Daley, Pratt, Torre \& Dario, 2018; Aitken \& Loads, 2019). It is useful to conceptualise identity for teaching in online environments to understand this dissonance. Online learning is often in the constructivist tradition compared to the more transmissive teaching often seen in lectures on campus (Bennett \& Lockyer, 2006), requiring different skills of staff for online teaching compared to that of teachers on-campus. A smooth transition to an online teaching role is important for several reasons. Jarvis (2015) describes experience as being 'conscious and socially constructed'. Those lacking experience of online learning and teaching require development to create expertise in this role in a social community. Developmental context is important. Being shaped by the community in which they work develops different facets of the individuals' own working identity: their teaching experiences, their learning experiences and their attitudes. Relational 
working with others - teachers and technologists - develops expertise and confidence in staff abilities for their online role, without creating dependence on others (Edwards, 2007). Without expert teachers, the quality of courses for students is diminished, and a likely rapid staff turnover due to lack of confidence results in succession planning difficulties.

To investigate the transition to online teaching, this study aims:

- To interpret the sense-making of experienced online teaching staff in their transition to online teachers

- To assess how previous experiences, whether training or teaching and learning in practice, impacted upon their identity as online teachers

- To use the findings for future staff development suggestions

The study was conducted prior to the COVID-19 pandemic. A small group of highly experienced staff, either actively engaged, or previously engaged with online teaching, were interviewed for their individual views of the transition to this role.

The research questions for this study were:

- What staff development and support did participants receive prior to, or during, their change to online learning and teaching?

- How did this development affect their ability to make sense of the transition to an online teaching identity?

- What experiences, both in the past, and in their role as an online teacher, influenced their current attitude to online learning and teaching?

The report on the findings, following interpretive phenomenological analysis, extends research into the development of an online teaching identity, providing suggestions for staff training to teach online, to enhance the student experience in ODL courses within this HEI. Lessons may be transferable to HEIs more widely, as greater use is made of the online mode post-COVID-19.

\section{Literature Review}

\subsection{Online Learning and Teaching}

For this paper, online courses are defined as learning delivered in an online environment via the internet, to students who are at a distance from the instructor, in-keeping with definitions discussed by Moore, Dickson-Deane \& Galyen (2011). This is entirely different to traditional face-to-face lecturing, where technology (the virtual learning environment) is used as a repository to store lecture slides, or emergency online teaching where materials are supplied online as recordings or synchronous sessions alone. Online teaching theory differs from face-to-face situations because the lack of immediacy in asynchronous learning requires different methods to engage students. Synchronous sessions differ from face-to-face, with continual eye contact causing fatigue, less body language expressivity and more 'queuing' to speak (Wiederhold, 2020).

Online teaching staff need to enable student socialisation (Salmon, 2007), important for collaborative learning, which may be facilitated by using tools such as discussion boards, blogs, and wikis in addition to synchronous sessions. Without the embodiment of lecturing, the teacher has to provide resources suitable to develop student knowledge. Not all staff have the continual assistance of an education technologist, so some technological know-how is also required. The online teacher is often less of the 'sage on the stage' found in face-to-face lecturing, and more shepherd-like, guiding students and encouraging them to form a learning community, constructing their own learning, without necessarily being 'present'. This constructivist approach has roots in Piaget's theory that development is dependent on the learner's active experiences, in addition to Vygotsky and Dewey's theory that learning is a social process with the learners' history of experiences in the past influencing knowledge (Mayer, 2009).

\subsection{Staff Development and Identity}

Staff development is a requirement for learning and teaching online (Salmon, 2007). To staff, identifying as subject specialists and face-to-face lecturers, the change required may be perceived as a threat to their professional identity (Brownell \& Tanner, 2012). There are a multitude of factors contributing to teaching identity. These include being a member of an established teaching community, having the skills associated with being an expert teacher, self-view, and previous life experiences (Lerserth, 2013). According to Lerserth (2013), self-view determines success. However, little attention has been given to change in identity to online from face-to-face teaching, manifest in staff self-view, or confidence in their abilities at the transition.

Staff are more likely to be trained in technology use rather than the pedagogy of online education (Owens, 2012). However, training availability and time for engagement with it varies. Methods employed are online courses, workshops and mentoring amongst others (Cramp, 2013; Campbell, 2016; Barczyk, Buckenmeyer, Feldman, \& Hixon, 2011). Greater student engagement occurs after effective staff training (Stephens \& Mottet, 2009). For HEIs to retain staff in an online 
role, staff must feel competent to carry it out; effective professional development can be transformational (Dempster, Benfield \& Francis, 2012). This is of importance when considering the methods and resources used for staff development as is shown by the study detailed below.

\section{Methods}

3.1 Phenomenology

Investigation of people's experiences lends itself to an inductive qualitative design. In this study, the experiences related by the participants were subjected to interpretive phenomenological analysis (IPA) allowing meaning to be made of the lived experience of a person (Smith, Flowers and Larkin, 2009). IPA is an interpretation of someone's experience, rather than an account of that experience, because researchers try to interpret others' 'sense-making' (Smith \& Osborn, 2007). It was deemed appropriate for this study as a method attempting to view others' experiences from their point-of-view. Previously, phenomenological studies have been used to investigate staff experiences in online teaching; e.g. Cornelius (2014) investigated staff experiences in synchronous virtual classrooms. Aitken and Loads (2019) investigated the experiences of staff starting to teach online postgraduate students. In the study described below, phenomenology is used to investigate how experienced staff handled their transition to online teaching.

\subsection{Interviews}

Five experienced staff involved, or formerly involved, in teaching on postgraduate online programmes were interviewed. This sample of staff were in an UK HEI in one faculty's Graduate School, teaching on three different programmes there. The sample was purposive as it used the appropriate population to sample for a study into the transition to online teaching and learning. It could also be described as convenience sampling, as all were known colleagues of the researcher. The sample was small due to the availability of staff members to participate in the interviews, although around five is not an unusual size of group for this type of study (Smith \& Osborn, 2007). Ethical approval was first obtained from the institution's preliminary ethics system, and informed consent received from the participants prior to their interviews.

Staff, recruited via email or in conversation with the researcher, were interviewed in-depth in person or online via Skype for up to one and a half hours each. Open-ended questioning in individual semi-structured interviews was guided by questions detailed below, developed by contemplating how to ensure experiences were captured to enable the aims of the study to be met. Additionally, they provided a non-threatening and empathetic atmosphere, enabling participants to be honest and reflective about their attitudes and feelings towards work, at the same time avoiding participant bias.

- Please could you tell me about your job.

- How did you get into teaching/tutoring/lecturing?

- What does 'teaching online' mean to you?

- Could you tell me about any training you have had?

- Do you think there are differences between online teaching and face-to-face? What makes you say that?

- Please describe a typical day when a course is running.

- How do you feel about your work as a lecturer?

- Do you feel different from when you first started?

- How do you see your future teaching career developing?

\subsection{Data analysis}

The full interviews were transcribed and uploaded to NVivo (QSR, 2016). IPA, detailed in Smith, Flowers and Larkin (2009), was carried out as a process, shown in figure 1. 


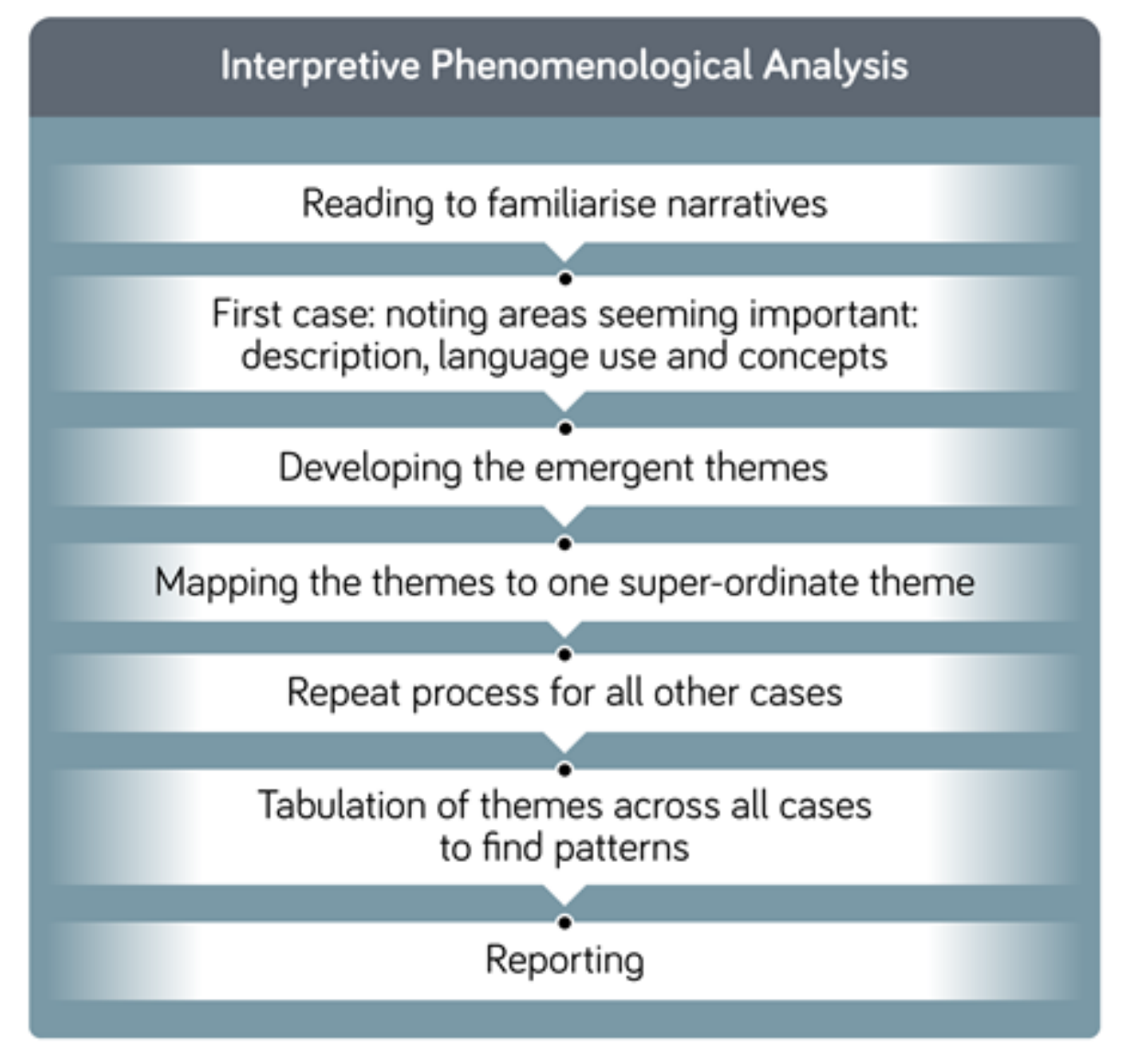

Figure 1. Flow diagram showing IPA process

The social context of the participants' transitions to online teachers in this institution, including interactions with other staff involved with online learning and teaching, was considered. The social context also covered rules or expectations governing the online teaching community, and how work is divided between the community's players. This is described in activity theory, which can be used as a tool in analysing the flow of work within a community (Engestrom, 2000).

\section{Findings}

\subsection{Interviewees}

The participants have been given the pseudonyms Clare, Frances, Kelly, Jane and Laura to maintain anonymity. They are, or had been, working in the Graduate School of a medical faculty in the UK as module leaders or associated roles in online masters programmes. Kelly no longer taught on Graduate School courses, although she continued to teach in faceto-face mode outside the university. She had taught an online module annually for four iterations. Frances had a nonteaching role in the Graduate School, but continued to run an online dissertation module in another institution. Clare, Jane and Laura, at the time of their interviews, had run modules in their specialist subjects for more than three years. Despite all being women, this was an incomplete reflection on the gender balance of online module leaders in this Graduate School. Outside teaching, the participants were clinicians or had other healthcare-related roles. All were subject specialists within the scope of their modules. Sieber (2005) describes the changing role of an online teacher from subject specialist to more of a guiding role but despite being less of the 'sage on the stage' entailed in face-to-face lecturing, subject specialists are still required online.

\subsection{Interpretive Phenomenological Analysis}

In carrying out IPA, whilst mapping the themes discovered in the analysis of the first case, the superordinate themes that appeared were community and connections, recurring as patterns across all the cases. The findings below provide evidence and details of these themes.

\subsubsection{Community: Face-to-face Teaching}

All participants were members of the face-to-face teaching community, being highly experienced in this mode of teaching as subject specialists. All were relaxed about this role, which held few stresses for them, having become experts after commencing teaching careers in this mode long before. 
Clare is a medic and a highly experienced clinical trainer in face-to-face situations, saying that this is an expectation of being a clinician:

'most of the clinical stuff is expected of you so if you're going to have trainees working with you, part of your role in supervising them is to try to help them become better doctors and learn about things that they haven't seen before'

'Helping people' was a common thread across participants with clinical-facing roles. The expectation was to teach others their speciality in face-to-face situations as their specialist knowledge became expert. Clare said she had a role model in the past:

'there was very definitely a consultant who I worked with when I was training... whose style...I thought I would aspire to'

Frances, Kelly and Jane were all invited to teach face-to-face, both formally and informally, due to their subject specialist knowledge. Only Laura found teaching more on the periphery of her research role, with a few lectures and seminars delivered to campus-based students annually. Laura was the only one of the participants to not mention enjoyment from face-to-face teaching sessions, the others showing enthusiasm for participating in this teaching community. For example, Clare commented:

'I really enjoyed it, getting involved in teaching and we frequently get emails coming round from the education centre saying we're short of two people to do seminar today, please can you help... and I say yes.'

Kelly also was enthusiastic, finding the formal study days she ran for multidisciplinary teams to be 'fun'. Both Frances and Jane emphasised their enthusiasm for teaching generally: 'I love it'.

In Clare's case, 'helping' pointed to helping in an offline, face-to-face community which she clearly identified with, rather than the online student community. For Kelly, the 'helping' was a face-to-face informal session, and direct email/Skype with consultants and general practitioners to improve knowledge of staff caring for patients.

Participants had all been in the face-to-face teaching community for more years, sometimes many more, than they had been in the online teaching community. They had received training for the face-to-face role, and their conversations showed this role was now firmly part of their identity. Clare's training was a postgraduate certificate in clinical education; Frances, Jane and Laura had participated in the local staff development courses provided by their institutions, either just before or as they started teaching face-to-face classes. These did not have elements for online learning and teaching. Only Kelly received no formal training, but it was something she thought nurses were expected to pick up as they went along, with seniority delivering an expectation to teach the less experienced, however informally. Likewise, any computer skills she had were not formally taught, but gained as the norm in her working community:

'I think about the computer skills you use on an everyday basis for a job...you never had any computer training whatsoever...you learn it on the job as it evolves, you learn off your mates'

\subsubsection{Community: Online Teaching and Learning}

Membership of the online teaching community required a transition to the different style of teaching, problematic for some of the participants. The new identity took time to develop, and a lack of time available may have slowed this further. In all the cases, the overwhelming impression was one of busy-ness in their working lives. Combining this workload with lack of time for exploration of resources, a barrier to full participation in the online education community is built. Kelly commented:

"my diary...it's almost set for next year...... things have to be really quite far in advance planned in, and whilst all the sort of telephone and email stuff is just done on the run all the time'

This does not bode well for ability to attend training courses and workshops.

Availability of training in online pedagogy and technology at the time of entry into the online community was said to be poor by all except Frances. Clare found the technology intimidating:

'Really scary.... suddenly you're on the university system it's nerve-wracking.'

Laura had some previous experience of being an online student in some of the more 'tick-box' types of courses, which failed to provide her with knowledge of the online teaching and learning community. She described these courses as:

'a very static thing, that you could access and download and watch'

Laura had heard of MOOCs (massive online open courses) but had not come across online degrees, so this community was entirely unfamiliar to her. She described taking over a module, previously run by someone else, without training:

'I was really quite terrified! And thought, oh my goodness, I've no idea what to do.....and actually realised quite quickly, and the module was about to start and I didn't have time.... before they were live and the students were querying' 
Likewise, Kelly was unsure of both technology and pedagogy when she started, again taking over someone else's module:

'I knew I wasn't competent doing the practical interface and setting up the content and the activities in the way in which I would have liked to have done them, which I think would really have enhanced what I was trying to teach.... I think in part that was my lack of skills in actually doing stuff because.... that's a whole new area of learning and I just didn't physically have the time to take on that learning really'

This led Kelly from initial enthusiasm for the challenge of online teaching to become frustrated.

Both Frances and Jane appeared to be full participants in the online teaching community, moving between the face-toface and online communities with complete ease. Both had been part of the online learning and teaching communities in student roles. Frances completed an online masters, subsequent to another masters degree taught face-to-face. She was enthused by the learning enabled by the online mode:

'The fact that I didn't just cram in the information and pound it out for an exam and it was all just forgotten...... your critical thinking around it is just fantastic, and you just keep digging in...so the learning became so much more meaningful for me than my first experience. And I loved that, I really loved that different way of learning .....and it meant I was much more engaged, a much more meaningful learning experience as a student.'

Frances had participated in a full month-long online staff development course providing training in technology and pedagogy at another institution, initiating her into the online teaching community. A mentor was provided for the first few weeks of teaching, consolidating her membership of this community.

Similarly, Jane had prior experience of being an online student which developed her experience of what 'good' online learning and teaching looked like:

'So, I'd been involved in being a recipient. So, I suppose all I did was bring...that knowledge...... I must have just thought this is how it should look'.

\subsubsection{Successful Connections with Online Teaching Communities}

There needs to be established connections to the online teaching community to join it. For these participants, connection was via other faculty already involved in teaching online or via learning technologists who help in course development. For example, Jane was well-connected to the online teaching community, first via an education technologist who had designed the course in conjunction with Jane and another subject specialist, then with an e-learning team administrator who helped with running and changes, meaning that she had very few technology issues despite a lack of training.

In discussing the differences between online and in-person pedagogy, Jane thought that good teaching was 'good teaching' no matter where it was. It was just in the practice of it these two communities differed. Jane enthused about the affordances of the online teaching community compared to the face-to-face offerings:

'I don't think there's a lot of difference between working online and teaching face-to-face. Except teaching online, I think there's more opportunity for engagement with the students.......Because if you are standing up there in a lecture theatre.... I could count on one hand the number of times that people have asked questions'

Frances had few worries, saying that whilst apprehensive at the start of her online career, this was mitigated by the training and the mentor:

'Did it seem daunting? Probably a little bit. So, I was also very grateful for having a mentor in the background, who was very good, who had been there for many years. I also had one of the most difficult students I've ever had in my very first class, so he helped me to deal with that as well'

Connection to the experienced mentor resulted in a high level of confidence for Frances in her transition to online teaching.

\subsubsection{Less Successful Connections with Online Teaching Communities}

Kelly had few connections to other online staff and technologists resulting in a battle to teach online. This was compounded by a lack of connection to the university, where Kelly's role was solely in teaching the module, whilst working in geographically distant situations, feeling isolated in her position. Interpreting that lack of connection lead to a loss of confidence in her teaching ability and difficulties with the transition to the online teaching identity. She commented:

'I really enjoyed the principle of it. I think the practice of it was much more challenging!'

An interpretation of Clare reaching out into the online teaching community was part of the willingness to say 'yes' in her desire to help, rather than a desire to fully take on the identity as a member of this community. She thought that the online learning and teaching community had much potential, unfulfilled due to economics, of providing education to healthcare 
staff in developing countries informed by her work in a hospital in Africa:

'And it's a shame that so many people could benefit from that learning but can't afford it. So that [free education] would be the way I see it going if I was going to do more of it, yeah.'

Clare's comments about technology being intimidating might have been elicited by her tenuous membership of the online teaching community, unable to fully understand its language. The idea of not knowing the terminology of technology for online teaching (mentioned specifically) made her feel diminished and unable to make the connection to cross the boundary of teaching types. Initially, she had little connection to the e-learning team who might have helped with understanding the technology. In contrast, her connection to her identity as a face-to-face teacher was very strong. She made a comment about online learning and teaching being different to face-to-face, feeling that online 'lacked the personal touch':

'I think it does feel very different to teaching in the old-fashioned sense.'

'Old-fashioned' teaching could be interpreted as an equivalent to 'the good old days', metaphorically replaced by a recent poor substitute. However, she enjoyed the flexibility of online teaching.

Laura felt there were major differences between teaching face-to-face and online, as well as a discomfort with understanding how her module fitted into the full masters programme. She described a feeling of bewilderment, which seemed to have abated once she had made connections with other online teaching staff:

'well, speaking to people like xxxx and yyyy, and people who've done it - their advice is really useful. And also getting the students' feedback and getting the previous year's and seeing what they liked, it was that kind of thing.'

\subsubsection{Gaining Experience with Greater Connections to Online Teaching Communities}

Once the participants had gained experience, as well as some staff development advice and training, they gained confidence in their approach to online learning and teaching. This included making deeper connections to the learning technology team in the Graduate School. Clare said she received training from the education technologist on using various technologies, as well as recent access to an online pedagogy development module:

'I feel I've got a much better handle of what is expected of me and what is expected of the students having had the module run a few times.'

Similarly, Laura found her confidence grew with experience, though time was still an issue:

'Well, a lot more confident than I did, but I still feel there is an enormous amount to learn and I'm also awfully conscious that I could improve it just a bit, you know if I just had the time, more time when I could make it a priority'

The prior lack of connection to the online community, who could have helped them gain confidence and knowledge, was evident in Laura and Clare's comments, although Clare 'self-helped' in learning the technology:

'you just need to have some time on it and click your way about. And certainly a few top tips or a sort of handy hints leaflet sort of explaining the terminology would.......maybe save some angst'

Laura described 'fumbling' her way around the virtual learning environment. It was two to three years of teaching before either she or Clare had any connections with the e-learning team, but from then on, they gained confidence, becoming more at home with their online identities. Laura, like Kelly, thought that the university had made the assumption that because she could teach face-to-face, she would be able to teach online just as easily, not providing a connection to those 'in the know' until long after Laura's online teaching had begun. Any training and advice were late, but well received, giving her confidence to act in her role online:

'certainly, now knowing where to go to ask, I feel comfortable with people and like seeing things that they've done well and think oh I could do that next time'

Kelly, whilst feeling more confident with later iterations of her module, did not connect with other staff or much training due to geography and workload:

'if you are actually someone who is working in clinical practice out of the area, that's the whole day taken up for me to get to [a training session] ...., do that hour and a half session and then come back again'

This was not the stated reason Kelly no longer teaches online; however, it may have been contributory. She thought assumptions had been made that if she could teach face-to-face, she would be able to teach online:

'I think it was just an assumption that you know your subject and you've been teaching, so you would somehow evolve to know how to do this. And actually, there was a clear knowledge and skills gap for me!'

This disconnection engendered isolation, and the under-developed knowledge of the norms of the university community appeared to leave Kelly feeling incompetent, lacking in confidence and stressed by the technology. 


\subsubsection{Connections with Students}

Clare keenly felt the lack of connection to students, compared to those in face-to-face situations where she could visibly see development occurring:

'when you've seen the same students on the ward.... you get a feel for their communication skills, you see how they interact with different people and patients.... umm.... you see them caught off the hoof just a little bit; they haven't had a chance to polish everything before it's loaded online for me to look at it. So, I think you get a better understanding of them because you're in the same room with them at the same time.'

Clare described a feeling of disconnect or detachment from her online students:

'the interactions that we have via the [VLE] and the, umm, blogs that they put up...it feels quite removed from teaching if you were in a small group with people...... it can be quite difficult to get that involved....'

Kelly developed a good connection with her online students:

'I got some quite interesting discussions going......either the second or the third year that I did it there were some really good discussions... sharing their experiences, and the others in the group say ooh, that's a bit unusual, and it obviously just piqued people's interest.'

Overall, the findings indicate that participants perceived development of knowledge of online teaching community practice, and being connected to members of the online community itself, affects their self-view of abilities and confidence in the transition to online teaching.

\section{Discussion}

The comments from the study participants illustrate the patchy support available for the staff development to enable online teaching identities to develop, as well as the effect this had on the participants perceptions and attitudes towards teaching online. Formal training was available for Frances as well as the experience of being an online student, both for a masters degree and for staff development. Jane used the experiences of being a student online to inform her identity development, as well as the aid of an education technologist and later, an e-learning administrator. Clare, Kelly and Laura initially received no support for development and lacked prior experience as online students. Their development was helped later in their careers as online teachers by interactions with e-learning technologists as relational working, occasional workshops and an online course.

When taking on the responsibility of running an online module, Clare, Kelly and Laura were barely in Vygotsky's 'zone of proximal development', the area where a learner needs help from others to be able to accomplish tasks, which they will be able to complete independently when their knowledge and experiences are complete (Shabani, Khatib \& Saman, 2010). Despite experience in face-to-face teaching, they lacked the social interaction, or connections, affording access to the online teaching community. Situated learning (Brown \& Duguid, 1991) taking place in a social context was non-existent, resulting in fear and lack of confidence shown by Laura and Clare, and frustrations felt by Kelly.

Consideration of the online teaching community as a community of practice, where there is an informal learning interaction between experts and novices, enabling novices to also become experts, described by Lave and Wenger (1991) is too simple for the participants in this study. It is more useful to consider in terms of Engestrom's (2000) activity theory. The transition from face-to-face teaching, with its own rules (or expectations and practices) and community to online teaching is a process forming an activity system, having rules or practices, and community consisting of other online teachers, e-learning technologists, administrators and Graduate School management, with the labour divided between the players. However, in the activity system in the cases of Clare, Kelly and Laura, some of the connections normally seen in the teaching transition activity system are absent, preventing the smooth transition to an online teaching identity. These novices already identify as expert teachers, but just not in the environment they are charged to work in.

To become members of the online teaching community, novices need to connect with the experts such as other online teachers and e-learning technologists, who have the experience and understanding of the practices of this community. These include how to use technology, constructivist pedagogy and connecting with students effectively (Bao, Selhorst, Moore \& Dilworth, 2018). This was available to Frances and Jane, but not to the others, at best leaving them in a liminal area. The lack of connection hampered the development of their online teaching identity to the point of leaving Clare tethered in the face-to-face community with 'old-fashioned teaching', rather than extending her identity to that of online teacher during the course's first iteration.

Staff development requires an interaction with more experienced staff via mediating tools such as courses, workshops and other resources required for the transition to online teachers as well as interaction for collaborative learning. Where this interaction failed to occur, work in the online teaching role was problematical, being described by the participants as 'terrifying' and 'scary'. The perception of Clare, Kelly and Laura that the university assumed they would be able to teach 
online without further development because they were experienced lecturers is common among staff tasked with changing to an online role. Cramp, (2013), cites Joyes, Hall and Thang (2008) who found that in practice many universities' staff transition to this role with little training. Anecdotally many staff are providing emergency online teaching with little or no training due to time available during the COVID-19 pandemic.

The prior experience of Frances and Jane of the community and practices surrounding the design and running of online courses made them more comfortable in the online mode than those without prior experience. The history of being an online student, who has learnt how good online courses run, helps develop the identity of the new online teacher via "preexisting personal understandings gained in other situations" as Hopwood \& Edwards (2017) describe the workplace construction of knowledge. This former identity ensured the route to an online teaching identity provided confidence: Frances had been a member of an activity system, albeit a different activity system (as student) and had seen how the teaching staff had acted in this system. It enabled her individual learning (the new identity development) as well as a systemic change (an increased population of online teaching staff), concurring with Edwards' comment that agency requires mutual responsibility as well as individual action (Edwards, 2007).

Jane lacked formal training, but her prior experience as a student on online courses, and working relationally with an elearning technologist, developed her identity as an online teacher to the point where she felt comfortable and confident. Both she and Frances stated their enjoyment of their online role, contrasting with the experiences of Clare, Kelly and Laura who, despite enthusiasm, failed to 'love' their online teaching. The barrier to online teaching identity development can be bridged by working relationally with experienced online teaching staff. In relational working for staff development, expertise is given to those less expert with the novice and expert remaining as equals (Hopwood \& Edwards, 2017).

The pressures of taking over from someone at the last-minute, leading to stress over a lack of pedagogical and technical knowledge, could be averted by good planning. Unfortunately, the instrumentalization of education has meant that staff have less time to spare with fewer people undertaking more (Maringe \& Sing, 2014). The repression of professional identity development by this system is another 'layer' which needs to be considered in the context of staff development. Clapp et al., (2019) suggested a series of steps to be taken in online course development, including planning staff training, which would avoid last minute calls upon inexperienced staff.

Frustration shown by Clare and Kelly at their lack of technical ability resulted from their initial lack of connection and collaboration with the online teaching community. Training should be ongoing and timely as technology tends to change from year to year with upgrades to software and newer technologies being used. Knowledge of, and training on, technology needs to be available by various means on a regular basis, as well as time to attend (Restauri, 2004). This requires a connection to the community, needing learning technologists or online pedagogical specialists available to 'knotwork'. Here, the online experts will work relationally to solve the problem of using technology, in conjunction with training the fledgling online teacher how to use it in the context of their online specialist subject course. They are not permanently bound as an activity system as this relational work only occurs when required, and knotworking is not necessarily governed by any particular rules (Engestrom, 2008, p20). Time for training is problematical; this could be avoided by having online materials as a 'just-in-time' resource. Encouragement of a mindset which enables growth would also be helpful in gaining confidence for technology use (Dweck, 2006, p33), replacing technophobic attitudes.

\subsection{Limitations and Ideas for Further Study}

IPA has enabled insights of how online teachers' experiences of the transition to an online teaching role affects their attitude towards online learning and teaching. The author is an experienced online teacher; Gadamer (1960) cited by Smith, Flowers and Larkin (2009) warns that we need to be aware of our own bias which will affect the interpretation. Whilst aware that the interpretation should be solely of these particular people's experiences within their particular context, some of the author's experiences were similar to that of Frances and Jane in the transition to experienced online teacher. In the role of an online student and with an informal mentor present early on in her online teaching career, she now trains staff to teach online via online courses, and may bring some preconceptions to the interpretation from this experience.

The choice of participants was heavily influenced by availability of staff for interviews. That more women generally are online lecturers reflects socialisation theory that 'pigeon-holes' individuals into specific roles governed by their gender by socialisation as children, leading to women entering careers with teaching and caring roles (Silander, Haake \& Lindberg, 2013). This is despite equal opportunities being the norm in this institution as well as in law in this country. The lack of other genders of participants is not a true reflection of the gender-balance of staff in the Graduate School, but merely a reflection of this study using convenience sampling. Further research using a greater number of participants and other genders could be useful.

These findings show that in the transition from teaching face-to-face to the online teaching community, timely support for staff development, or its' lack, influenced the attitudes of those interviewed for this study. 


\section{Conclusions}

IPA was used to uncover the attitudes, perceptions and practicalities involved in the transition to an online role for Graduate School staff. It has been successful in that the study aims of capturing their previous experiences, and how participants made sense of the experience of becoming an online teacher, have been met. The results lead to a conclusion that good training and interaction with other online teachers and education technologists is essential in the development of an online teaching identity. Whilst it has long been known that good training is required, this study adds knowledge of how stressful it can be for staff left to complete this transition alone, which may impact them and their students.

The confidence shown by Frances, who had received the most extensive training, suggests that an online course plus a mentor is a very successful combination. Online courses provide situated learning, enabling staff to experience the same parameters as students. Provision of a mentor, or availability of an e-learning team for online learning development, to also provide advice, is quite common in online programmes, where it is beneficial for subject specialist staff not to be sole course designers (Restauri, 2004). However, it needs to be made explicit that this help is available.

This study has used activity theory to theorise the opportunities and challenges faced by staff in the transition to an online teaching role, and inform the conclusions. Prior history of the community as online students, and training, enables a confident transition to their new identity. Relational agency is a powerful means of developing identity for new online teachers interacting with more experienced staff in this community.

The author as an online teacher may have brought bias into the interpretation. That all the participants were known to her would have aided their confidence to speak the truth known to them, and using open questions avoided influencing responses (Smith \& Noble, 2014). Selection bias is possible, but all the Graduate School online teachers are known to the researcher, so this would occur whoever was invited to participate from the school.

Around the time of this investigation, an online module for staff development was designed for new online teaching staff with an experienced mentor (the researcher) available as tutor. Future research will be conducted to evaluate its success, and sections have indeed been used to inform part of the cross-university online staff development course during COVID19. For many other institutions, the COVID-19 pandemic has forced staff development into online courses, which this study's results suggest is a good move, provided enough experienced staff such as educational technologists are available for interaction, enabling staff to develop their online teaching identities. Post-COVID-19, universities should not make the assumption that staff have the skills for full online teaching, as opposed to emergency teaching online, but provision needs to be made to connect staff with the online teaching communities for collaborative induction into this role. The role requires the provision of time for training, as well as development of resources for students, whether it is for full online programmes or blended learning. A good transition will develop a self-view of competence enabling staff to be positive about their identities as online teachers.

\section{Acknowledgements}

The author would like to thank Professor Liz Todd and Dr Laura Delgaty for advice on the manuscript, and Ashley Reynolds for enhancing the author's figure 1 in Adobe Illustrator. Thanks are also extended to the participants.

\section{References}

Aitken, G., \& Loads, D. (2019). Experiences of staff new to teaching postgraduate students online: implications for academic staff development. Journal of Perspectives in Applied Academic Practice, 7(1), 37-46. https://jpaap.napier.ac.uk/index.php/JPAAP/article/view/361/533

Bao, M., Selhorst, A. L., Moore, T. T., \& Dilworth, A. (2018). An Analysis of Enhanced Faculty Engagement on Student Success and Satisfaction in an Online Classroom. International Journal of Contemporary Education, 1(2), 25. https://doi.org/10.11114/ijce.v1i2.3653

Barczyk, C., Buckenmeyer, J., Feldman, L., \& Hixon, E. (2011). Assessment of a University-Based Distance Education Mentoring Program from a Quality Management Perspective. Mentoring \& Tutoring: Partnership in Learning, 19(1), 5-24. https://doi.org/10.1080/13611267.2011.543567

Bennett, S., \& Lockyer, L. (2006). Becoming an Online Teacher: Adapting to a Changed Environment for Teaching and Learning in Higher Education. Educational Media International, 41(3), 231-248. https://doi.org/10.1080/09523980410001680842

Brown, J. S., \& Duguid, P. (1991). Organizational Learning and Communities-of-Practice: Toward a Unified View of Working, Learning and Innovation Special Issue: Organizational Learning Organization Science, 2(1), 40-57. https://doi.org/10.1287/orsc.2.1.40

Brownell, S. E., \& Tanner, K. D. (2012). Barriers to faculty pedagogical change: Lack of training, time, incentives, and...tensions with professional identity? CBE Life Sciences Education, 11(4), 339-346. 
https://doi.org/10.1187/cbe.12-09-0163

Campbell, A. (2016). Talking Point - Flexible Targeted Online Staff Development that Works. Journal of Interactive Media in Education (1), 1-10. http://dx.doi.org/10.5334/jime.395

Clapp, A, Reynolds, A., Bell, B., Lockhart, E., Todd, G., \& Connell, T. (2019). Planning the Development and Maintenance of Online Distance Learning Courses. Online Journal of Distance Learning Administration, 22(1). https://www.westga.edu/ distance/ojdla/spring221/clapp_reynolds_bell_lockhart_todd_connell221.html

Clapp, A. (2017). An e-learning team's life on and offline: A collaborative self-ethnography in postgraduate education development. Electronic Journal of E-Learning, 15(1).

https://academic-publishing.org/index.php/ejel/article/view/1817

Clay (1999) Development of Training and Support Programs for Distance Education Instructors Online Journal of Distance Learning Administration 2, 3 https://www.learntechlib.org/p/90061/

Cornelius, S. (2014). Facilitating in a demanding environment: Experiences of teaching in virtual classrooms using web conferencing. British Journal of Educational Technology, 45(2), 260-271. https://doi.org/10.1111/bjet.12016

Cramp, A. (2013). Meaningful dialogue in digitally mediated learning for in-service teacher development. Technology, Pedagogy and Education, 24(1), 1-16. https://doi.org/10.1080/1475939X.2013.822417

Dempster, J. A., Benfield, G., \& Francis, R. (2012). An academic development model for fostering innovation and sharing in curriculum design. Innovations in Education and Teaching International, 49(2), 135-147. https://doi.org/10.1080/14703297.2012.677595

Dweck, C (2006) Mindset: the new psychology of success New York, Ballantine Books

Edwards, A. (2007). Relational Agency in Professional Practice: A CHAT analysis. Actio: An International Journal of Human Activity Theory, 1, 1-17. https://doi.org/10.1080/02601370500169178

Engestrom, Y (2008) Teams and the transformation of work, in Engestrom, Y (Ed) From Teams to knots: activity theoretical studies of collaboration and learning at work New York, Cambridge University Press https://doi.org/10.1017/CBO9780511619847

Engestrom, Y. (2000). Activity theory as a framework for analyzing and redesigning work. Ergonomics, 43(7), 960-974. https://doi.org/10.1080/001401300409143

Hopwood, N., \& Edwards, A. (2017). How common knowledge is constructed and why it matters in collaboration between professionals and clients. International Journal of Educational Research, 83, 107-119. https://doi.org/10.1016/j.ijer.2017.02.007

Jarvis, P. (2015). Learning expertise in practice: Implications for learning theory. Studies in the Education of Adults, 47(1), 81-94. https://doi.org/10.1080/02660830.2015.11661676

King, E., \& Boyatt, R. (2015). Exploring factors that influence adoption of e-learning within higher education. British Journal of Educational Technology, 46(6). https://doi.org/10.1111/bjet.12195

Lave, J., \& Wenger, E. (1991). Situated Learning. UK, Cambridge University Press. https://doi.org/10.1017/CBO9780511815355

Lerseth, K. A. (2013). "Identity development among pre-service teacher candidates". Doctoral thesis; Graduate Theses and Dissertations. 13200 Iowa State University https://lib.dr.iastate.edu/etd/13200

Maggio, L. A., Daley, B. J., Pratt, D. Torre, D., \& Dario, M. (2018) Honoring thyself in the transition to online teaching, Academic Medicine, 93, 8, 1129-1134 https://doi.org/10.1097/acm.0000000000002285

Maguire, L. (2005). Literature review - faculty participation in online distance education: barriers and motivators. Online Journal of Distance Learning Administration, 8(1), 1-15.

https://www.westga.edu/ distance/ojdla/spring81/maguire81.htm

Maringe, F., \& Sing, N. (2014). Teaching large classes in an increasingly internationalising higher education environment: pedagogical, quality and equity issues. Higher Education, 67, 761-782.

https://doi.org/10.1007/s10734-013-9710-0

Mayer, S. J. (2009). Dewey's dynamic integration of Vygotsky and Piaget. Education and Culture, 24(2), 6-24. https://doi.org/10.1353/eac.0.0026

Moore, J. L., Dickson-Deane, C., \& Galyen, K. (2011). E-Learning, online learning, and distance learning environments: Are they the same? Internet and Higher Education, 14(2), 129-135. https://doi.org/10.1016/j.iheduc.2010.10.001 
Owens, T. (2012). Hitting the nail on the head: the importance of specific staff development for effective blended learning. Innovations in Education and Teaching International, 49(4), 389-400. https://doi.org/10.1080/14703297.2012.728877

QSR (2016) NVivo $12 \mathrm{http} / / /$ www.qsrinternational.com/

Restauri, B. S. L. (2004). Creating an effective online distance education program using targeted support factors. Tech Trends, 48(6), 32-39. https://doi.org/10.1007/BF02763580

Rolfe, V., Alcocer, M., Bentley, E., Milne, D., \& Meyer-Sahling, J. (2006). A study of staff attitudes towards electronic learning in arts and sciences. Proceedings of the European Conference on Games-Based Learning, 317-322.

Salmon, G. (2007). 80:20 for E-Moderators. Cms-Journal, 29, 39-43. https://eprints.usq.edu.au/18862/2/Salmon_Ch16_2006_PV.pdf

Shabani, K., Khatib, M., \& Saman I. (2010). Vygotsky's zone of proximal development: instructional implications and teachers' professional development. English Language Teaching, 3(4), 237-248. https://doi.org/10.1016/j.compedu.2018.05.013

Sieber, J. E. (2005). Misconceptions and realities about teaching online. Science and Engineering Ethics, 11(3), 329-340. https://doi.org/10.1007/s11948-005-0002-7

Silander, C., Haake, U., \& Lindberg, L. (2013). The different worlds of academia : a horizontal analysis of gender equality in Swedish higher education. Higher Education, 173-188. https://doi.org/10.1007/s10734-012-9597-1

Smith, J. A., \& Osborn, M. (2007). Pain as an assault on the self: An interpretative phenomenological analysis of the psychological impact of chronic benign low back pain. Psychology and Health, 22(5), 517-534. https://doi.org/10.1080/14768320600941756

Smith, J., \& Noble, H. (2014). Bias in research. Evidence-based Nursing, 17(4), 100-102. https://doi.org/10.1136/eb-2014-101946

Smith, J. A., Flowers, P., \& Larkin, M. (2009). Interpretative Phenomenological Analysis: Theory, Method and Research. UK, Sage

Stephens, K. K., \& Mottet, T. P. (2009). Interactivity in a web conference training context: effects on trainers and trainees. Communication Education, 57(1), 88-104. https://doi.org/10.1080/03634520701573284

Wiederhold, B. K. (2020). Connecting through technology during the Coronavirus disease 2019 pandemic: avoiding "Zoom fatigue." Cyberpsychology, Behavior, and Social Networking, 23(7), 437-438.

https://doi.org/10.1089/cyber.2020.29188.bkw

\section{Copyrights}

Copyright for this article is retained by the author(s), with first publication rights granted to the journal.

This is an open-access article distributed under the terms and conditions of the Creative Commons Attribution license which permits unrestricted use, distribution, and reproduction in any medium, provided the original work is properly cited. 